\title{
X-chromosomal inactivation analysis of uterine leiomyomas reveals a common clonal origin of different tumor nodules in some multiple leiomyomas
}

\author{
YI-RAN CAI ${ }^{1}$, XIAO-LI DIAO ${ }^{2}$, SHU-FANG WANG $^{2}$, WEI ZHANG ${ }^{2}$, HONG-TU ZHANG $^{1}$ and QIN SU $^{1,2}$ \\ ${ }^{1}$ Department of Pathology, Cancer Hospital, Chinese Academy of Medical Sciences and Peking \\ Union Medical College, Beijing 100021; ${ }^{2}$ Department of Pathology, Tangdu Hospital, \\ the Fourth Military Medical University, Xi'an, Shaanxi 710038, P.R. China
}

Received May 18, 2007; Accepted July 16, 2007

\begin{abstract}
Uterine leiomyomas were shown to be clonal lesions, but the relationship among different tumor nodules in multiple uterine leiomyomas remains unresolved. In this study, X-chromosomal inactivation patterns of these tumor nodules were shown by allelic polymorphism analysis through polymerase-chain reaction at the phosphoglycerate kinase and androgen receptor loci following pretreatment with the methylation-sensitive restriction enzyme $\mathrm{HpaII}$ or HhaI. A total number of 113 cases of uterine leiomyomas were examined. Monoclonality was demonstrated in all of the 315 nodules from 76 informative cases. The inter-nodular relationship was evaluated in 55 multiple cases with 294 tumor nodules. Different inactivation patterns were observed in 20 cases, demonstrating a multicentric origin, while an identical inactivated allele was found in all or most of the nodules in the rest of the cases, indicating a common clonal origin. The occurrence of the unicentric cases appeared to be associated with an elevated mitotic activity. Seven nodules from a multinodular case with a morphology indicative of mitotically active leiomyoma were shown to carry the identical inactivated allele, which demonstrates their unicellular origin and malignant nature. In addition, the same androgen receptor gene alteration was identified in two discrete leiomyoma nodules from a uterus. These results approve the monoclonality of uterine leiomyomas and demonstrate the presence of unicentric multiple leiomyomas.
\end{abstract}

Correspondence to: Professor Qin Su, Department of Pathology, Cancer Hospital, Chinese Academy of Medical Sciences and Peking Union Medical College, Panjiayuan Nanli 17, Beijing 100021, P.R. China

E-mail: q.su@wjgnet.com

Key words: uterine leiomyomas, multiple, inter-nodular relationship, clonality analysis, phosphoglycerate kinase gene, androgen receptor gene, $\mathrm{X}$-chromosome inactivation

\section{Introduction}

Uterine smooth muscle neoplasm is one of the most common tumors in females, whose prevalence among adults ranges from $20 \%$ (1) to $70 \%(2,3)$. It is frequently benign. However, tumors showing histologic features intermediate between clearly benign leiomyomas and leiomyosarcomas, namely mitotically active leiomyomas (4-7), smooth muscle tumors of uncertain malignant potential $(8,9)$ or atypical leiomyoma (10), are not rare, and their clinical behavior cannot be predicted reliably $(11,12)$. The distinction between benign and malignant behavior is further blurred by the presence, even though infrequent, of intravenous leiomyomatosis (IVL) $(13,14)$, benign metastasizing leiomyoma (BML) (14-18) and disseminated peritoneal leiomyomatosis (DPL) $(19,20)$.

There is often more than one tumor observed in cases of uterine leiomyoma. It remains to be settled as to whether all of these tumors are fully independent (multicentric) or most of the nodules originate from a parent tumor by cell migration or spreading (unicentric). While most of the reports favor the former possibility (21-28), the data from our group, obtained in 15 multiple leiomyomas using X-chromosomal inactivation analysis, have indicated that, in some cases, different tumor nodules may share a common clonal origin (29). Actually, identical genetic alterations and $\mathrm{X}$-chromosomal inactivation patterns were also observed incidentally in different leiomyomas from the same uteri by other authors $(27,30,31)$. A better understanding of the relationship between multiple tumor nodules may be helpful for distinguishing the borderline neoplasms from the clearly benign leiomyomas. In the current study, monoclonality was revealed in all of the 318 smooth muscle tumor nodules from 76 cases, and the relationship between different nodules was evaluated in 55 multi-nodular cases with 297 lesions by their X-chromosomal inactivation patterns.

\section{Materials and methods}

Samples. Fresh tissue samples were obtained by 113 hysterectomies for uterine corpus neoplasms in Tangdu Hospital, Xi'an from February 1998 to August 2001. The study protocol 
was approved by the Medical Ethics Commission of the Fourth Military Medical University in Xi'an. Sampling was finished within $40 \mathrm{~min}$ after the uterus was taken from patients. All tumors were excised. Four specimens of apparently normal smooth muscle tissue $\left(5 \mathrm{~mm}^{3}\right)$ adjacent to each of the tumor nodules were used as controls. The tissues were stored at $-70^{\circ} \mathrm{C}$.

Histological and immunohistochemical examinations. Each sample was examined histologically for the parenchyma/ mesenchyma ratio on $4-\mu \mathrm{m}$ paraffin sections stained with hematoxylin and eosin. Samples with admixed mesenchymal cells $>20 \%$ of the total nucleated cells were excluded from the assay. All cases were examined separately by three pathologists (Q. Su, S.-F. Wang and W. Zhang) according to the reported criteria $(3-5,11,12,32)$. The multiple leiomyomas were examined for the histologic variants including atypical (bizarre), myxoid types and those with pronounced hyaline degeneration (32). Mitotic figures were counted within 50 randomly selected high-power fields (HPF), and mitotic indices were calculated and expressed as number of mitotic figures/ $10 \mathrm{HPF}$.

For the samples suspected for leiomyosarcoma, immunostaining was also conducted, as described previously (33), to identify their differentiation pathways. Following deparaffinization and rehydration, serial sections were treated with $0.3 \%$ of hydrogen peroxide in $80 \%$ methanol for $30 \mathrm{~min}$, blocked using $3 \%$ of preimmune goat serum in $10 \mathrm{mM}$ phosphatebuffered saline ( $\mathrm{pH} \mathrm{7.4)}$, and incubated overnight at $4{ }^{\circ} \mathrm{C}$ with mouse monoclonal antibodies against smooth muscle actin, desmin, CD10 and vimentin (Dako A/S, Glostrup, Denmark). The reactions were demonstrated using a peroxidase-labeled streptavidin-biotin kit (K0675; Dako A/S) and visualized in a buffer containing $0.5 \mathrm{mg} / \mathrm{ml} \mathrm{3,3'-diaminobenzidine} \mathrm{and} 0.01 \%$ hydrogen peroxide for $15 \mathrm{~min}$. The sections were lightly counterstained with hematoxylin, dehydrated, and mounted in neutral resinous medium.

Principles of X-chromosomal inactivation analysis. There are two $X$ chromosomes within each somatic cell in females, one from the father $\left(\mathrm{X}^{\mathrm{p}}\right)$ and another from the mother $\left(\mathrm{X}^{\mathrm{m}}\right)$. Both $\mathrm{PGK}$ and $\mathrm{AR}$ genes are located in $\mathrm{X}$ chromosomes, showing readily demonstrable polymorphism in different frequencies. The former carries a BstXI restriction-polymorphic site, reflecting the G/A single-nucleotide polymorphism (SNP) at exon 1 (34), while the latter is polymorphic at the CAG short-tandem repeat (STR) (35). These allelic differences enable us to discriminate $\mathrm{X}^{\mathrm{p}}$ from $\mathrm{X}^{\mathrm{m}}$.

During embryogenesis, one of the $\mathrm{X}$ chromosomes in each somatic cell in females is inactivated through methylation, while the genetic activity of the second $\mathrm{X}$ chromosome is preserved throughout life. As the inactivation is random, in all females somatic cells can be divided into two types, one with the inactivated paternal PGK and AR alleles, named Type A, and another with the inactivated maternal alleles, termed Type B. The inactivation is rather stable, and the inactivated allele of a cell can be transmitted to its daughter cells including those undergoing neoplastic transformation (36). The clonality status of the somatic female cells, therefore, can be determined based on the X-chromosomal inactivation mosaicism (37). Loss of the $\mathrm{X}$-chromosomal inactivation mosaicism, therefore,
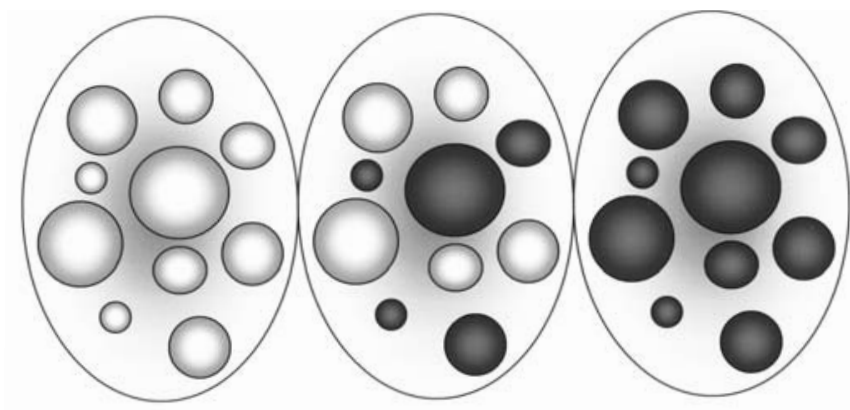

Type A

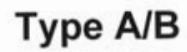

Type B
Figure 1. Inter-nodular relationships determined by the $\mathrm{X}$-chromosomal inactivation patterns. In cases with multiple leiomyomas, all tumors showing the identical inactivated allele, i.e. belonging to the cell type A with an inactivated paternal allele (Type A) or the cell type B with an inactivated maternal allele (Type B), were considered unicentric, while coincidental occurrence of the type A and type B tumors in the same case (Type A/B) indicated their multicentric, independent nature.

can be demonstrated by the allelic imbalance using SNP analysis at the PGK locus through BstXI digestion or STR length estimation at exon 1 of the $\mathrm{AR}$ gene on denaturing polyacrylamide gels.

As depicted in Fig. 1, each inactivated allele at $\mathrm{X}^{\mathrm{p}}$ or $\mathrm{X}^{\mathrm{m}}$, both for PGK and AR loci, should be detected at the same frequency in uterine smooth muscle tumors. Hence, occurrence of tumors composed of transformed type A cells and those of type B cells should be at similar incidences, if the tumors themselves are fully independent from each other, and frequencies of coincidental occurrence of type A or that of type B representation in two, three, four, five and six independent tumors should be $25 \%, 12.5 \%, 6.25 \%, 3.13 \%$ and $1.56 \%$, respectively. For the multiple lesions, therefore, it should be safe to regard five or more tumor nodules carrying an identical inactivated allele as unicentric, i.e., sharing a common parent clone. It is also reasonable to consider that three or more tumor nodules with identical inactivation patterns as demonstrated at both PGK and AR loci are most probably of unicentric origin.

Primers used to amplify $P G K$ and AR genes. Two primer pairs were used for amplifying PGK gene exon 1 (29) (PGK1A: 5'CTG TTC CTG CCC GCG CGG TGT TCC GCA TTC -3'; PGK1B: 5'- ACG CCT GTT ACG TAA GCT CTG CAG GCC TCC -3'; and PGK2A: 5'- AGC TGG ACG TTA AAG GGA AGC GGG TCG TTA -3'; PGK2B: 5'- TAC TCC TGA AGT TAA ATC AAC ATC CTC TTG -3'). Two primer pairs were for amplifying AR gene exon 1 (29) [AR1A (221+): 5'- GAG GAG CTT TCC AGA ATC TG -3'; AR1B (454-): 5'- CAT GGG CTT GGG GAG A -3'; and AR2A (230+): 5'- TCC AGA ATC TGT TCC AGA GC -3'; AR2B (446-): 5'- TGG GGA GAA CCA TCC TCA CC -3'].

Pretreatment with HpaII and amplification for the PGK gene. One-mm thick tissue specimens, as large as $5 \mathrm{~mm}^{2}$ or through the largest cross-section, were minced separately. Genomic DNA was isolated using an extraction kit (QIAamp, Qiagen $\mathrm{GmbH}$, Hilden, Germany) as described previously (29). The 
DNA extracts from tumors and the non-neoplastic smooth muscle tissues, $10 \mu 1$ each, were incubated with $5 \mathrm{U}$ of $\mathrm{HpaII}$ (Promega, Madison, WI, USA) at $37^{\circ} \mathrm{C}$ for $12 \mathrm{~h}$ in a volume of $20 \mu \mathrm{l}$ containing $0.2 \mu \mathrm{l}$ of $10 \mathrm{mg} / \mathrm{ml}$ bovine serum albumin (BSA) and $2 \mu 1$ of $10 \mathrm{X}$ reaction buffer, and heated at $95^{\circ} \mathrm{C}$ for $5 \mathrm{~min}$ to inactivate the enzyme. The digested DNA samples, $5 \mu \mathrm{l}$ each, were then subjected to nested polymerase-chain reaction (PCR). The reaction mixture was $50 \mu 1$ in volume, containing $4 \mu \mathrm{l}$ of $10 \mathrm{mM}$ dNTP (Gibco BRL, Life Technologies, Inc., Gaithersburg, MD, USA), primers PGK1A and PGK1B (0.4 pmol each), $5 \mu 1$ of $10 \mathrm{X}$ buffer, $1.5 \mu 1$ of $50 \mathrm{mM}$ $\mathrm{MgCl}_{2}$ and $2.5 \mathrm{U}$ of Taq DNA polymerase (Gibco BRL). The amplification was conducted using a PT-200 thermocycler (MJ Research, Inc., Watertown, MA, USA) for 35 cycles $\left(94^{\circ} \mathrm{C}, 40 \mathrm{sec} ; 58^{\circ} \mathrm{C}, 50 \mathrm{sec} ; 72^{\circ} \mathrm{C}, 1 \mathrm{~min}\right)$. The PCR mixture (1 $\mu \mathrm{l}$ ) was then seeded to the second reaction mixture with PGK2A and PGK2B as primers. The reaction was conducted for 35 cycles $\left(94^{\circ} \mathrm{C}, 40 \mathrm{sec} ; 56^{\circ} \mathrm{C}, 50 \mathrm{sec} ; 72^{\circ} \mathrm{C}, 1 \mathrm{~min}\right)$.

Detection of BstXI restriction-polymorphism of the PGK products. The PCR products, $10 \mu 1$ each, were incubated at $47^{\circ} \mathrm{C}$ for $8-10 \mathrm{~h}$, in a mixture of $20 \mu 1$ in volume containing $5 \mathrm{U}$ of BstXI (Promega), $0.2 \mu \mathrm{l}$ of $10 \mathrm{mg} / \mathrm{ml} \mathrm{BSA}$ and $2 \mu \mathrm{l}$ of $10 \mathrm{X}$ reaction buffer. The digested products were then resolved in $2 \%(\mathrm{~g} / \mathrm{ml})$ agarose gel containing ethidium bromide $(0.2 \mu \mathrm{g} / \mathrm{ml})$, and visualized under ultraviolet light. Images were recorded using an image-acquisition system (UVP, Inc, Upland, CA, USA). Sizes of products were determined by a 100-bp DNA ladder (Gibco BRL), fluorescence intensities of the products at the positions of $530 \mathrm{bp}$ and $433 \mathrm{bp}$ were assessed using the analysis software LabWork 3.0 (UVP).

Pretreatment with HhaI or HpaII and amplification for the AR gene. Genomic DNA extracts, $10 \mu 1$ each, were incubated with $10 \mathrm{U}$ of $\mathrm{HhaI}$ (Promega) at $37^{\circ} \mathrm{C}$ for $3 \mathrm{~h}$ in a volume of $20 \mu 1$ containing $0.2 \mu 1$ of $10 \mathrm{mg} / \mathrm{ml} \mathrm{BSA}$ and $2 \mu 1$ of $10 \mathrm{X}$ reaction buffer, and heated at $65^{\circ} \mathrm{C}$ for $20 \mathrm{~min}$ to inactivate the enzyme. HpaII-pretreatment, as described above, was also used in some samples to ensure reliability of the reaction, as inconsistent results have been observed regarding HhaIand HpaII-pretreatment (38). The digested DNA samples, $5 \mu 1$ each, were then subjected to nested PCR, with AR1A and $\mathrm{AR} 1 \mathrm{~B}$ as primers for the first round, AR2A and AR2B as primers for the second round, and $56^{\circ} \mathrm{C}$ as the annealing temperature for both reactions.

Resolving AR products by denaturing polyacrylamide gel electrophoresis. The efficacy of the PCR for the AR gene was assessed by electrophoresis on $2.0 \%$ agarose gels. The amplification products, $3 \mu 1$ each, were mixed with the same volume of sample buffer ( $99 \%$ formamide, $1 \mathrm{mg} / \mathrm{ml}$ bromophenol blue, and $1 \mathrm{mg} / \mathrm{ml}$ xylene cyanol), and then resolved on the $10 \%$ polyacrylamide gel containing $8.0 \mathrm{M}$ urea at $80 \mathrm{~V}$ for $8 \mathrm{~h}$ using the Hoefer MiniVE apparatus (Amersham-Pharmacia Biotech, Inc., San Francisco, CA, USA). For those with allelic variations as small as one or two CAG repeats, the size difference could not be clearly visualized on the 8-cm long gel, and then the samples were loaded onto a $0.75-\mathrm{mm}$ thick gel as long as $26 \mathrm{~cm}$ and resolved using the Hoefer SE660 apparatus (Amersham Bioscience Corp., San
Francisco, CA, USA) for $26 \mathrm{~h}$ at a voltage of $150 \mathrm{~V}$. Gels were fixed for $4 \mathrm{~min}$ in $10 \%$ ethanol containing $0.5 \%$ acetic acid, treated with $10 \%$ nitric acid for $4 \mathrm{~min}$, washed in deionized water for $4 \mathrm{~min}$, and then impregnated in $0.6 \%$ silver nitrate for $45 \mathrm{~min}$. After rinsing the gel in deionized water for $5 \mathrm{~min}$, the reaction was visualized in a solution containing $3 \%$ sodium carbonate and $0.1 \%$ formaldehyde for $5 \mathrm{~min}$. After being soaked in $10 \%$ acetic acid for $5 \mathrm{~min}$, the gel was washed in deionized water for $5 \mathrm{~min}$. The reaction was recorded using the image-acquisition system and an ordinary optical camera. Sizes of products were determined using 100-bp and 10-bp DNA ladders (Gibco BRL).

Cloning and sequencing of PCR products. Selected amplification products of PGK, all migrating at $530 \mathrm{bp}$ or at $433 \mathrm{bp}$, were cloned and sequenced to verify the specificity of the Bst XI cleavage reaction. Representative PCR products for AR exon 1 were also analyzed by sequencing in order to correlate their migration behaviors and CAG repeat numbers. All aberrant amplification products were cloned and sequenced to identify the underlying structural alterations.

Evaluation of data and statistical analysis. For both reactions for the PGK and AR genes, a reduction of $\geq 50 \%$ in their signal intensities for the products of either allele, as compared to those obtained using the samples not treated with HpaII or HhaI, is regarded as loss of $\mathrm{X}$-chromosome inactivation mosaicism (29). Each reaction was repeated at least once to guarantee the reproducibility. Moreover, parallel assays were made using non-neoplastic smooth muscle samples of comparable sizes from four different sites of the same uterus as controls. In addition, adjacent smooth muscle tissues, ranging from 1 to $10 \mathrm{~mm}^{2}$ in size and as thick as $1 \mathrm{~mm}$, from 6 uteri were also subjected to the assay at PGK locus in order to exclude possible interference of clonal patches to the evaluation of data as encountered by other authors (39-41).

Statistical analyses were carried out using the software package SPSS 10.0 (SPSS, Inc, Chicago, IL, USA). The mitotic indices of different types of multiple leiomyomas were expressed as median values. Their difference was determined by the two-sided Wilcoxon rank-sum test (42). Relationships between the types and histologic variants were described by t-test and Pearson $\left(\chi^{2}\right)$ tests. $\mathrm{P}<0.05$ was regarded as being statistically significant.

\section{Results}

Non-neoplastic smooth muscle tissues from the 113 uteri were subjected to PCR. A PGK-specific product was obtained in all the cases, digestion with BstXI showing its polymorphism in $34(30 \%)$. Frequently, the band migrating at 530 bp was stronger than the lower one at $433 \mathrm{bp}$, with their ratio being approximately 3:1 (Figs. 2 and 3), as noted previously (29). Among the 34 cases with polymorphism at the PGK locus, $6(18 \%)$ showed marked allelic skewing $(29,43)$, and were excluded from the following assay.

In order to approve the specificity of PCR and the accuracy of $B s t$ XI digestion, amplification products from cases 77 and 78 were cloned and their sequences were determined. Both of the samples were shown on gels to be homozygous for the 


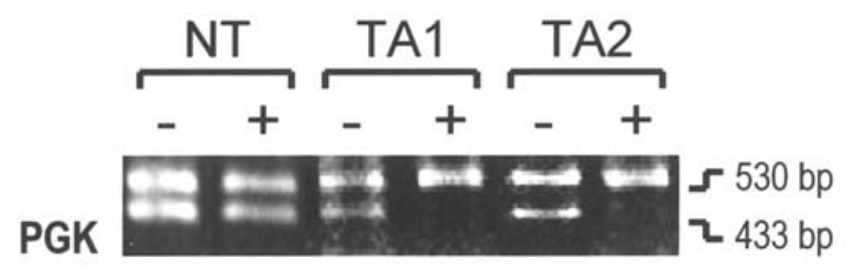

AR

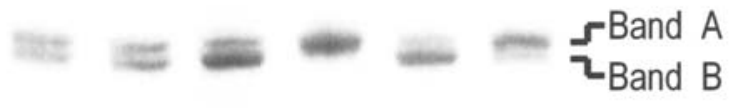

Figure 2. Parallel assays on X-chromosomal inactivation, using the polymorphic sites at PGK and AR loci, in a uterine leiomyoma, case 12, showing monoclonality for tumor samples from two separate areas (TA1 and TA2), but not in the non-neoplastic smooth muscle tissue (NT). The G/A singlenucleotide polymorphism at PGK gene exon 1 was demonstrated by BstXI digestion and electrophoresis on an agarose gel containing ethidium bromide. The intact and cleaved amplification products migrate at positions of 530 and $433 \mathrm{bp}$, respectively (upper). The length polymorphism of exon 1 of the AR gene was resolved on a $10 \%$ polyacrylamide gel containing $8 \mathrm{~mol} / \mathrm{l}$ urea and visualized by silver staining, with one product (Band B) migrating faster than the other (Band A; lower). Pretreatment with HpaII or HhaI (-, before; + , after), respectively for the PGK and AR assays, resulted in loss (TA1, TA2 for the PGK assay and TA1 for the AR assay) or marked reduction (only TA2 for the AR assay) of one band in tumor samples, but not in the non-neoplastic tissue (NT).

BstXI site, giving rise only to a band of $530 \mathrm{bp}$ for the former case and $433 \mathrm{bp}$ for the latter. Sequencing data showed that both products were from exon 1 of the PGK gene, being in accordance with the data reported previously $(44,45)$. As demonstrated by $B s t$ XI digestion, a difference was found at position 438 from the 5 '- end between these 2 samples, with adenosine at this position for case 77 , and guanosine at this position for case 78 .

In total, 101 (89\%) of the 113 cases examined were found to be length-polymorphic at exon 1 of the AR gene, showing two products migrating between positions of 190- and 240-bp DNA markers on the denaturing polyacrylamide gel (Figs. 2 and 4). Sixty-three (62\%) of the polymorphic cases, with 287 tumors, were suitable for the subsequent assay, and 38 (38\%) were excluded for the following reasons: i) the allelic lengthvariation was too small for precise assessment in 33 cases; ii) marked skewing between two AR alleles in 4 cases; and iii) structural alteration in one of the AR alleles identified in one case. However, the mutation in the latter case (case 79), with two tumor nodules, provided another parameter to describe their inter-nodular relationship, as detailed below.

Combining these two reactions, 76 of the 113 samples $(67 \%)$ were suitable for X-chromosomal inactivation analysis, whereas only $28(25 \%)$ or $63(56 \%)$, respectively, were suitable when either the assay for the PGK gene or that for the AR locus were used.

Among the 76 informative cases examined, 21 were found to carry a single tumor nodule, and 55 showed multiple leiomyomas with 2 ( 20 cases) or $>2$ ( 35 cases) tumor nodules. A total number of 318 tumors were examined using the PGK or/and AR assays, with 315 being informative. Three tumors from case 46, with massive hyalinization, were excluded from the analysis. Loss, or a pronounced reduction, of one band was observed for all the samples after the pretreatment with HpaII or HhaI, reflecting their monoclonality (Figs. 2-4).

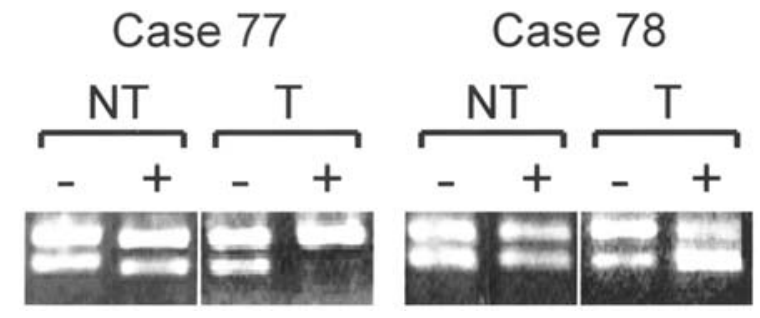

Figure 3. PGK clonality analysis in two cases of uterine leiomyomas, cases 77 and 78. Pretreatment with HpaII (-, before; +, after) resulted in loss (Case 77) or marked reduction (Case 78) of one band in tumor samples (T), but not in the non-neoplastic smooth muscle tissue (NT).

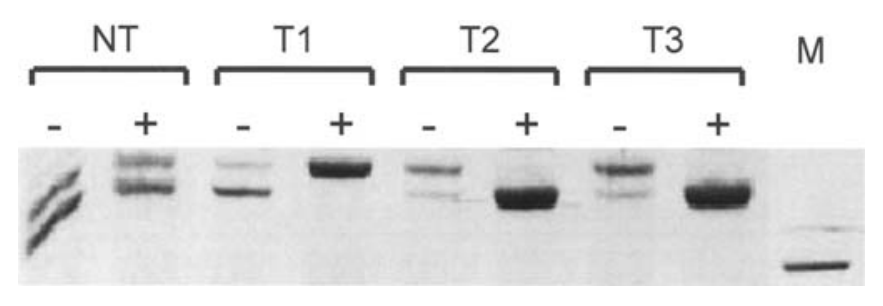

Figure 4. AR clonality analysis of three leiomyomas (T1-T3) found in a uterus (case 29). Pretreatment with HhaI (-, before; +, after) resulted in loss of one band in tumor samples, but not in the non-neoplastic smooth muscle tissues (NT). The right lane (M) shows a 200-bp DNA marker.

Table I. X-chromosomal inactivation patterns of different tumor nodules in 55 cases of multiple uterine leiomyomas.

\begin{tabular}{cccc}
$\begin{array}{c}\text { Tumor } \\
\text { nodules } \\
(\mathrm{n})\end{array}$ & $\begin{array}{c}\text { Cases } \\
\text { examined } \\
(\mathrm{n})\end{array}$ & $\begin{array}{c}\text { Case } \\
\text { codes }\end{array}$ & $\begin{array}{c}\text { Cases with identical } \\
\text { allele inactivated in all } \\
\text { (or most) nodules (n) }\end{array}$ \\
\hline 2 & 20 & $01-20$ & 14 \\
3 & 11 & $21-31$ & 7 \\
4 & 3 & $32-34$ & 3 \\
5 & 5 & $35-39$ & $1(3)$ \\
6 & 4 & $40-43$ & 3 \\
7 & 3 & $44-46$ & 1 \\
8 & 2 & 47,48 & $0(2)$ \\
9 & 2 & 49,50 & $0(1)$ \\
12 & 1 & 51 & 0 \\
16 & 1 & 52 & 0 \\
17 & 1 & 53 & 0 \\
28 & 1 & 54 & 0 \\
32 & 1 & 55 & 0 \\
\hline
\end{tabular}

Reproducibility of the results was ensured by taking more than one sample from different areas within tumors $>1 \mathrm{~cm}$ in diameter. Consistent results were obtained for all of the cases examined (Fig. 2). In order to exclude possible pitfalls in the interpretation of the results by ignoring clonal patches, 221 samples of the adjacent smooth muscle tissue of different sizes were taken from six uteri and subjected to the assay for PGK locus. The tissues with $10-\mathrm{mm}^{2}(\mathrm{n}=6)$ and $5-\mathrm{mm}^{2}(\mathrm{n}=42)$ 
Table II. PGK and AR allele inactivation patterns in cases with $\geq 4$ tumor nodules.

\begin{tabular}{|c|c|c|c|c|c|}
\hline \multirow[t]{2}{*}{ Case codes } & \multirow[t]{2}{*}{ Nodules (n) } & \multicolumn{2}{|c|}{ PGK allele at } & \multicolumn{2}{|c|}{ AR alleles at } \\
\hline & & upper band (n) & lower band (n) & upper band (n) & lower band (n) \\
\hline 32 & 4 & 0 & 4 & 0 & 4 \\
\hline 33 & 4 & - & - & 0 & 4 \\
\hline 34 & 4 & - & - & 4 & 0 \\
\hline 35 & 5 & 0 & 5 & 0 & 5 \\
\hline 36 & 5 & - & - & 4 & 1 \\
\hline 37 & 5 & - & - & 4 & 1 \\
\hline 38 & 5 & - & - & 1 & 4 \\
\hline 39 & 5 & - & - & 2 & 3 \\
\hline 40 & 6 & 6 & 0 & - & - \\
\hline 41 & 6 & 6 & 0 & - & - \\
\hline 42 & 6 & - & - & 0 & 6 \\
\hline 43 & 6 & - & - & 2 & 4 \\
\hline 44 & 7 & 2 & 5 & 2 & 5 \\
\hline 45 & 7 & - & - & 3 & 4 \\
\hline 46 & 7 & 0 & 7 & 0 & 7 \\
\hline 47 & 8 & - & - & 1 & 7 \\
\hline 48 & 8 & - & - & 7 & 1 \\
\hline 49 & 9 & 8 & 1 & - & - \\
\hline 50 & 9 & 4 & 5 & 4 & 5 \\
\hline 51 & 12 & - & - & 4 & 8 \\
\hline 52 & 16 & 4 & 12 & - & - \\
\hline 53 & 17 & - & - & 9 & 8 \\
\hline 54 & 28 & - & - & 16 & 12 \\
\hline 55 & 32 & - & - & 19 & 13 \\
\hline
\end{tabular}

-, data non-informative due to the lack of polymorphism or marked allelic skewing.

cross-sections did not show identifiable allelic differences in the signal intensity ratio by HpaII-pretreatment. However, imbalance of the X-chromosomal inactivation was observed in 3-, 2-, and 1- $\mathrm{mm}^{2}$ samples at frequencies of $14 \%(6 / 42)$, $19 \%(8 / 42)$ and $28 \%$ (25/89), respectively, its occurrence being closely associated with the sample size examined $(\mathrm{F}=5.807$, $\mathrm{P}<0.01)$. The data showed that clonal patches are indeed present in the uterine leiomyogenic tissues. The patch sizes should be much smaller than $5 \mathrm{~mm}^{2}$ in cross-section. Therefore, patching cannot interfere with the evaluation of data with the procedures employed in this study (Fig. 5).

A total number of 297 tumor nodules were found in the 55 multiple leiomyomas examined (5.4 nodules per case in average). The relationship among different tumor nodules in multiple cases, as revealed by their inactivated PGK and AR alleles, appeared to be associated with the nodule numbers (Tables I and II). For the cases with $>10$ tumor nodules (cases 51-55), a nearly random distribution was observed between the number of tumors carrying the inactivated $\mathrm{X}^{\mathrm{p}}$ and that with the inactivated $\mathrm{X}^{\mathrm{m}}$, indicating their multicentric, independent origins.
For the cases with 4 to 10 tumor nodules (cases 32-50), a unicentric origin will be considered if all tumor nodules share the same inactivated PGK and/or AR alleles. As listed in Table I, the 19 cases examined were divided into three types according to their inter-nodular relationships: i) the multicentric type (cases 39, 43-45, and 50), with the two alleles randomly inactivated among different lesions as listed in Table II; ii) the unicentric type (cases 32-35, 40-42 and 46), with all lesions sharing the same inactivated allele as shown in Fig. 6; and iii) the concomitant occurrence of the unicentric and multicentric types in 6 cases (cases 36-38, and 47-49; Table II), with only one nodule carrying a different inactivated allele as shown in Fig. 7.

Among the unicentric multiple cases, case 46 was a $43-$ year-old woman when admitted to the hospital. Multiple masses were detected in her uterus and a hysterectomy was performed. Grossly, 10 apparently discrete nodules sizing from 15 to $30 \mathrm{~mm}$ were found in the uterine corpus, with myxoid appearance in some areas. Microscopic examination showed features characteristic of the smooth muscle tumor. This was confirmed by its immunoreactivities for vimentin, 


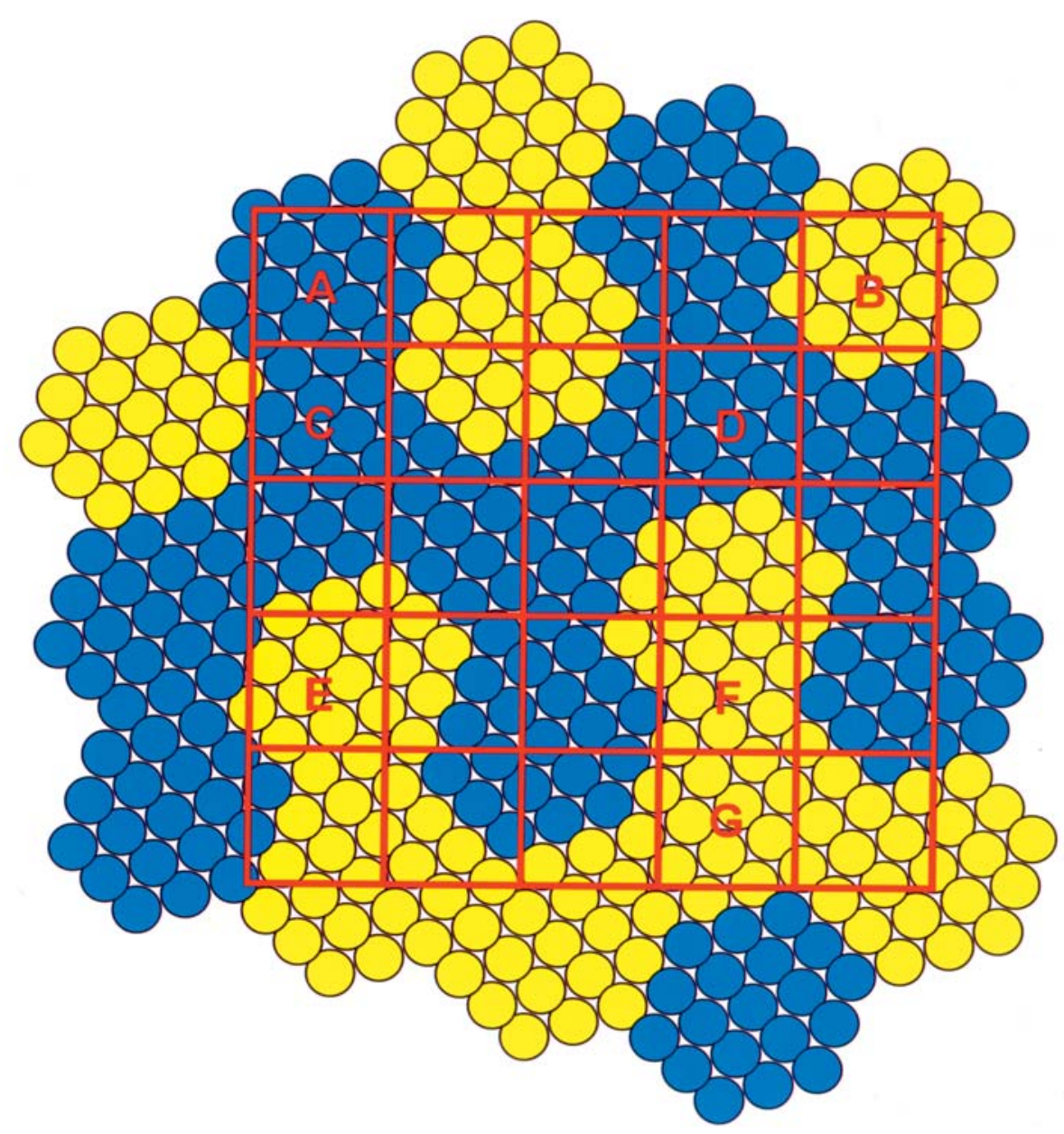

Figure 5. Tissue size requested for the clonality analysis based on X-chromosomal inactivation mosaicism as a negative control, in consideration of clonal patches in uterine myometrium. The patches composed of type A cells (white) and those of type B cells (gray) are distributed randomly, each size is $\sim 2 \mathrm{~mm}$ in diameter according to the data from the current study. The frame, $5 \mathrm{~mm}^{2}$, reflects the sample size requested for the clonality assays in the study, covering 20 patches, clearly demonstrating the mosaicism in non-neoplastic tissues. However, for the samples of $1 \mathrm{~mm}^{2}$, as represented by the smallest square, 7 of the 25 squares (28\%) fall into the area occupied completely (A, B, D and G) or mostly (C, E and F) by the same cell type. With areas of 2 and $3 \mathrm{~mm}^{2}$ considered, the frequencies decrease to $12.5 \%(2 / 16)$ and $11 \%$ (1/9), respectively, taking the sensitivity of the PGK clonality assay as showing allelic imbalance with the examined sample containing $>50 \%$ of monoclonal cells (29), i.e. with the ratio of two cell types $>3: 1$.

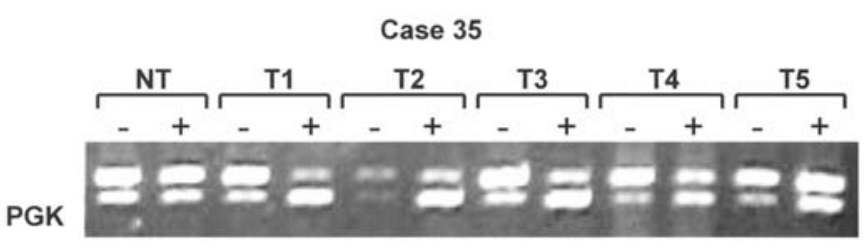

AR

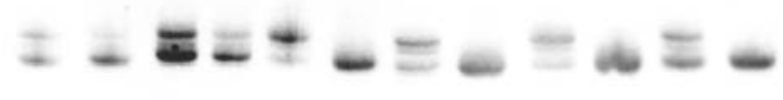

Case 41

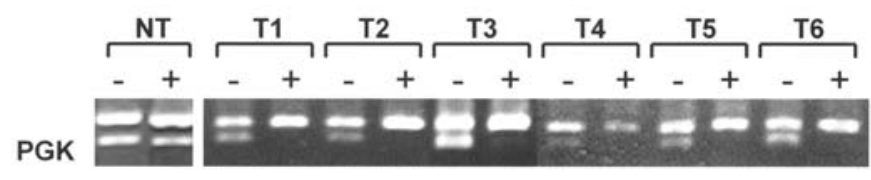

Figure 6. Multiple leiomyomas of the unicentric type, cases 35 and 41 with 5 (T1-T5) and 6 tumor nodules (T1-T6), respectively, demonstrated by Xchromosomal inactivation analysis at both PGK and AR loci for the former case, and only at the PGK locus for the latter. Identical PGK and AR alleles were preserved through the pretreatment (-, before; +, after) with the restriction enzymes HpaII and HhaI, respectively. NT, non-neoplastic smooth muscle tissue.

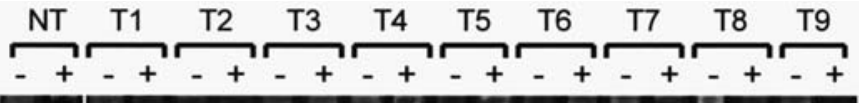

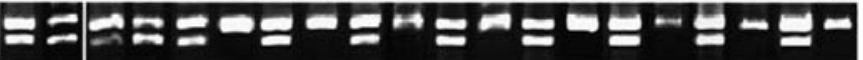

Figure 7. A multiple uterine leiomyoma of the mixed type (case 51), with the PGK allele, recognizable by BstXI, preserved through the pretreatment with HpaII (-, before; +, after) in only one tumor nodule (T1), the other allele was preserved in all of the remaining 8 nodules (T2-T9). NT, non-neoplastic smooth muscle tissue.

smooth-muscle actin and desmin, and its negativity for CD10. Focal myxoid change and massive hyaline degeneration were observed, with mild nuclear atypia in focal areas (Fig. 8A). A mitotic index of 14/10 HPF (56/40 HPF) was found in more cellular areas. Mitotically active leiomyoma was proposed for the case. Then, the sample was subjected to the Xchromosome inactivation assays. Among these ten nodules, PCR was successfully conducted in 7 , the others failed because of massive hyalinization (Fig. 8B). As shown in Fig. 9, similar inactivated alleles were found in all of these 

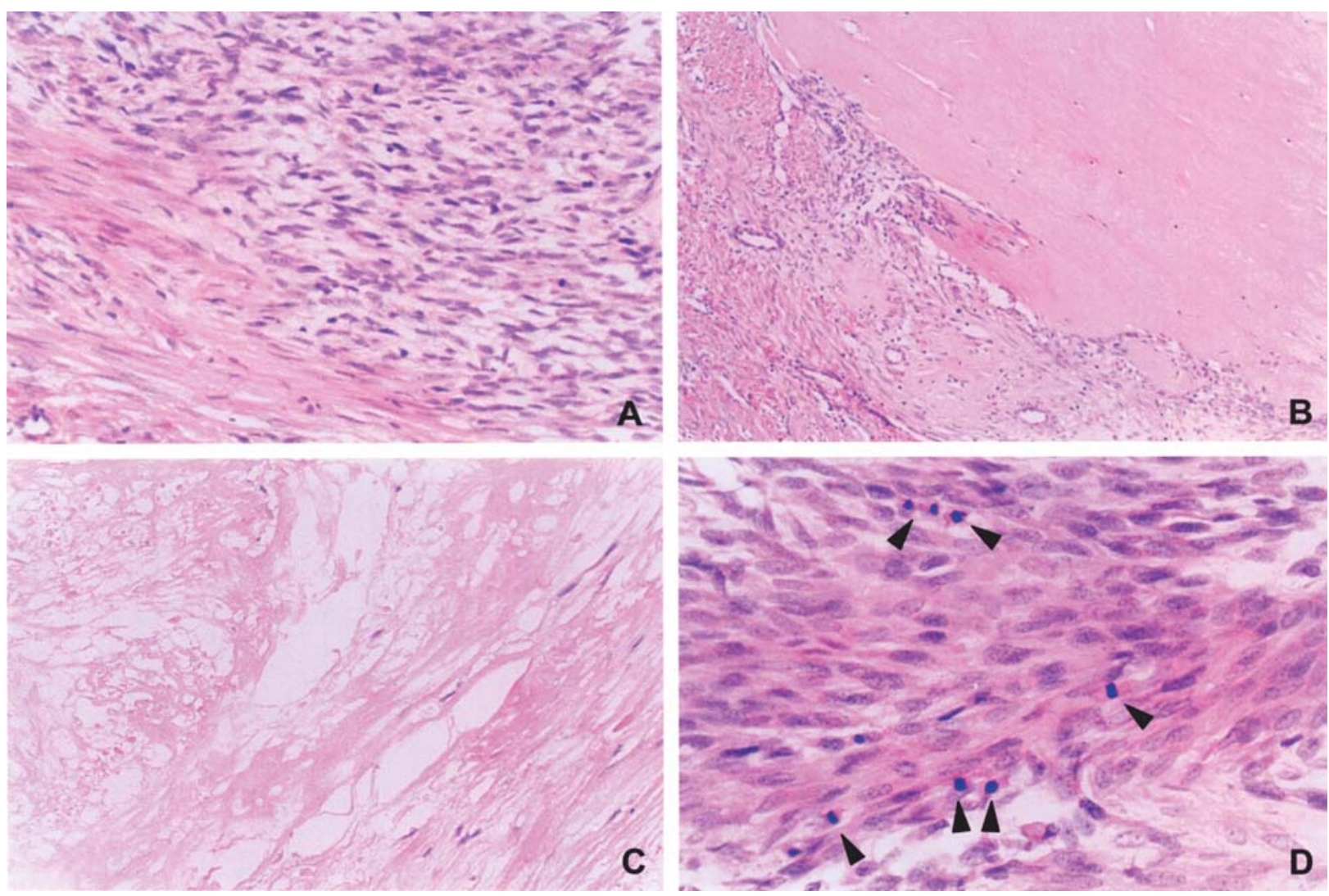

Figure 8. Micrographs of case 46 with 10 tumor nodules, considered a mitotically active leiomyoma during the preliminary examination (A and B), proven to be a leiomyosarcoma by re-sampling (C and $\mathrm{D}$ ) following the X-chromosomal inactivation assay (see Fig. 9). (A) More cellular tumor area composed of spindle cells, with its leiomyogenic phenotypes demonstrated by positive immunoreactivities for smooth muscle actin and desmin (data not shown). (B) Tumor area showing massive hyalinization, with an osteoid appearance. (C) Tumor area with coagulative necrosis. (D) Highly cellular area with more mitotic figures (arrowheads). Magnification: A and C, x240; B, x120; D, x480. Stained with hematoxylin and eosin.

\section{$\stackrel{\mathrm{NT}}{\mathrm{T} 1} \underset{-+}{\mathrm{T} 2}+\frac{\mathrm{T} 3}{+} \underset{-+}{\mathrm{T} 4} \stackrel{\mathrm{T} 5}{+} \underset{-+}{\mathrm{T} 6} \underset{-+}{\mathrm{T} 7} \mathrm{M}$ bp

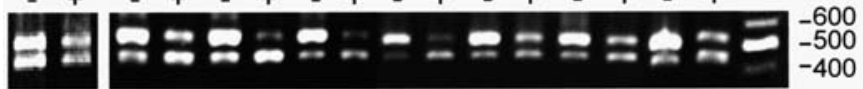

Figure 9. X-chromosomal inactivation patterns of 7 tumor nodules (T1-T7) examined in case 46 , a multinodular leiomyogenic tumor as illustrated histologically in Fig. 8. Allelic imbalance was present at the PGK locus, all with the same inactivated, BstXI-recognizable allele preserved through the pretreatment with HpaII (-, before; +, after). The right lane was loaded with DNA markers (M), its size denoted in bp. NT, non-neoplastic smooth muscle tissue.

samples, demonstrating a common clonal origin for the 7 nodules examined. The multi-nodular appearance simply reflected intramural spreading of the tumor cells, and the aggressiveness of this tumor. Focal coagulative necrosis (Fig. 8C) and highly cellular areas (Fig. 8D) were found by re-sampling and further examination. A final diagnosis of leiomyosarcoma was made.

Among the 20 cases with two tumor nodules and suitable for the X-chromosomal inactivation analysis, 14 (70\%) showed the same inactivated PGK or AR allele (Table I). Three of them were examined by both assays at the PGK and AR loci, with concordant results demonstrated in two and different data obtained in one. Of the 11 cases with three tumor nodules, four $(46 \%)$ showed different $\mathrm{X}$-chromosomal inactivation patterns (Fig. 4), and 7 (64\%) were found to carry the same inactivated allele, with consistent results obtained for both the PGK and AR loci in one of them. It is evident that the identical inactivation pattern in three discrete lesions from the same uterus frequently, if not always, reflects a common parental cell origin.

Considering the limitations in evaluating the inter-nodular relationships in cases with only a few tumor nodules, the presence of an identical gene mutation or the same chromosomal alteration, which occurs otherwise rarely, would be strong evidence for a unicentric origin of different tumors in the same patient. Fortunately, it was encountered in a multiple case (case 79) with two grossly discrete tumors. Loss of heterozygosity $(\mathrm{LOH})$ was observed in these two tumor nodules, the larger product being undetectable. An aberrant amplification product was found in both samples, migrating at the position corresponding to that of the 190-bp DNA marker (Fig. 10). The products from tumors and adjacent smooth muscle tissues were cloned and sequenced. Those from the smooth muscle tissue showed homology to the AR gene as compared to the reported sequence (46-48), the CAG repeat number of the smaller and larger products being 21 and 23 , respectively. A deletion mutation within the STR was detected in the aberrant products from both tumors, with the CAG repeat number being reduced to 11 .

Forty-nine cases of multiple leiomyomas were examined for their mitotic activity and histologic variants, with one (case 46) 


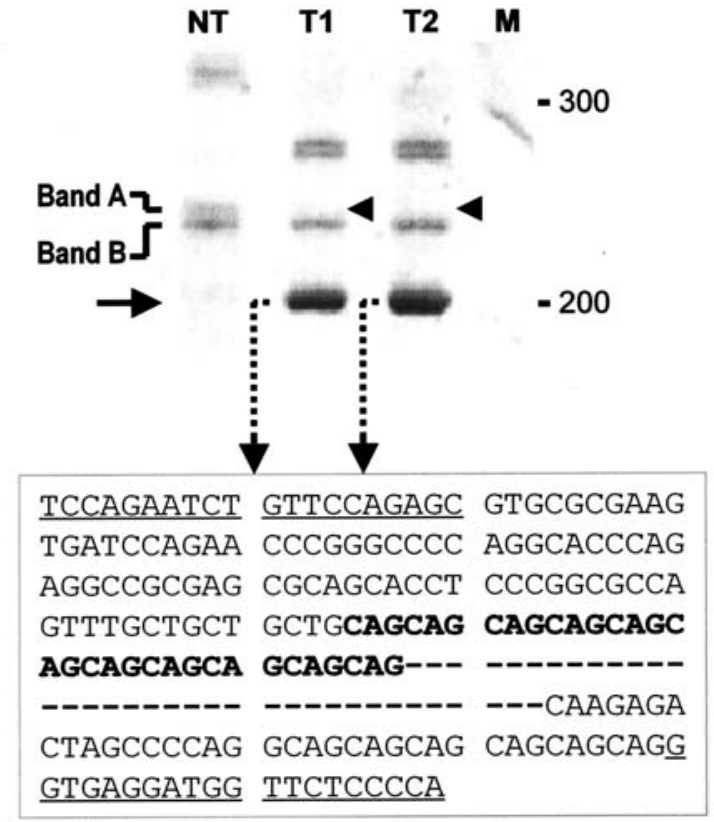

Figure 10. Loss of heterozygosity at AR exon 1 in both of the tumor nodules (T1, T2) from case 79. Allelic length polymorphism at the AR locus was visualized on the denaturing polyacrylamide gel (upper) in the nonneoplastic smooth muscle tissue (NT). Loss of band A (arrowheads) and occurrence of an aberrant product (arrow) migrating at the position corresponding to the 190-bp DNA marker (M) were seen in samples from both tumor nodules. Sequencing data were shown in the frame (low). A 36-base deletion, represented by dash lines, was found within the short-tandem repeat (bold) in the aberrant products from both tumors compared to Band A from NT. Positions of primer pair AR2A/AR2B are underlined.

excluded from the test for its obvious malignant behavior as described above. The mitotic counts were not $>2 / 10$ HPF in 48 cases and reached 2.6/10 HPF in one. Median indices for the unicentric-/mixed-type cases and the multicentric-type tumors were $0.6 / 10 \mathrm{HPF}$ and $0.2 / 10 \mathrm{HPF}$, respectively. The mitotic activity appeared significantly elevated $(\mathrm{Z}=2.424, \mathrm{P}=0.015)$ in the former compared to the latter group. No association was observed between mitotic index and the numbers of tumors $(\mathrm{P}>0.05)$. In addition, no statistical significance was found between the inter-nodular relationship and the histologic changes, including nuclear pleomorphism $\left(\chi^{2}=1.918, \mathrm{P}>0.05\right)$, myxoid $\left(\chi^{2}=1.367, P>0.05\right)$ and hyaline degeneration $\left(\chi^{2}=0.453\right.$, $\mathrm{P}>0.05)$.

Follow-up was conducted for the 55 multiple cases, ranging from 64 to 112 months (78 months in average). Metastases were found in case 46 with the multi-nodular leiomyosarcoma 24 months after the hysterectomy (July, 2000), involving ovaries, lungs, liver and skin. The patient died 28 months after surgery. No recurrence or metastasis was observed for the other cases till April 2007.

\section{Discussion}

It has been proposed that uterine leiomyomas are monoclonal in their cell composition $(23,24,29,37,48)$. Hence, the development of this neoplasm is considered a process of clonal expansion of an altered leiomyogenic cell. In the present study, we examined 315 leiomyomatous nodules from 76 cases using X-chromosomal inactivation analysis at the PGK and AR loci, and provided strong evidence for the view.

Considering possible interference with the clonal cell clusters occurring under physiological and pathological conditions $(39-41,48)$, we demonstrated the patches in the non-neoplastic smooth muscle tissue. Their sizes were shown to be $<5 \mathrm{~mm}^{2}$, most probably ranging from 2 to $3 \mathrm{~mm}^{2}$ in crosssection, as estimated by comparing the observed frequencies of X-chromosomal inactivation mosaicism in the samples and its probabilities in a representative, albeit simplified, model as depicted in Fig. 5. The data clearly demonstrated the reliability of the assay with the control samples covering an area of $5 \mathrm{~mm}^{2}$.

While most of the uterine leiomyomas appear benign, some rare cases $(1-3 / 1000)$ can progress to leiomyosarcoma $(49,50)$. Different chromosomal alterations were identified in both types of lesions by comparative genomic hybridization (51). In addition, there are more cases showing histologic features intermediate between them (4-10). These lesions often cause diagnostic problems, because their clinical behavior cannot be predicted with certainty $(11,12)$.

The relationship between different tumor nodules in multiple uterine leiomyomas remains a matter of debate. Recent observations on three leiomyogenic proliferative diseases related to the multiple uterine leiomyoma, including DPL, IVL and BML, have demonstrated the common clonal origin of different lesions and apparently associated the unicentric feature to their clinical aggressiveness. DPL has been shown to be neoplastic. An identical inactivated $\mathrm{X}$ chromosome was found in all of its extrauterine leiomyogenic proliferative nodules and the intramural leiomyoma (20). Consistent cytogenetic alterations were found in most of the nodules examined as well $(19,20)$. These data reveal the disseminating or metastatic feature of the neoplasm. A study by Quade et al (52) on IVL demonstrated the same Xchromosomal inactivation pattern in different lesions within and outside the uterus. Chromosome translocation $(12,14)$ (q15;q24), a frequent cytogenetic alteration in uterine leiomyoma (53), was also observed in all of these nodules. The same X-chromosomal inactivation pattern was demonstrated in uterine tumors and all pulmonary tumorlets from the BML cases $(17,54)$, supporting the view that pulmonary lesions are metastatic $(15,16)$. In consideration of these findings, the relationship among different tumor nodules in the multiple leiomyomas may also reflect their biological behavior.

While most authors favor a multicentric origin of different tumors in multiple uterine leiomyomas based on cytogenetic $(22,23,25)$ and $\mathrm{X}$-chromosomal inactivation analyses $(21,23,24,26-28)$, macroscopically discrete tumors occurring in the same uterus were incidentally observed to share the same inactivated PGK or AR allele and identical cytogenetic alterations by a few groups in a limited number of cases $(19,27,29-31)$. In the present study, 55 cases of multiple leiomyomas were examined for their X-chromosomal inactivation patterns. Random inactivation patterns were revealed among different tumor nodules from 20 (36\%) of these cases, indicating their independent, multicentric origins. In 29 (53\%) of them, however, the identical inactivated allele was found in all tumor nodules from the same uterus. Obviously, the occurrence of the same X-chromosomal inactivation pattern 
in different tumors may be a fortuitous event in some of these cases. This is particularly true for those with two tumors. In the latter cases, however, presence of the identical AR gene mutations in different tumors adds a piece of strong evidence for the unicentric origin, as the incidence of this genetic event is $<0.7 \%(2 / 287)$ and the probability for its coincidental occurrence in two independent tumors from the same uterus is $<0.005 \%(0.7 \% \times 0.7 \%)$.

Among the 55 multiple cases examined, 6 (11\%) showed an inactivated allele in one tumor and another inactivated allele in all of the remaining nodules, comprising a mixed type. In these cases, one of two preexisting genotypically different, independent tumors may acquire invading or migrating capacity and hence give rise to several daughter nodules with identical genotype.

The results of our study, for the first time, provide strong evidence for the presence of unicentric multiple uterine leiomyomas, even though the definite incidence remains to be elucidated. The results indicate that, at least in some of the cases, most tumor nodules developed from one parent tumor cell clone by migration or spreading of the neoplastic cells, which means that some of the unicentric multiple leiomyomas are potentially aggressive. This is further evidenced by the elevated mitotic activity observed in the unicentric multiple leiomyomas.

It remains to be settled whether the mitotically active leiomyoma is more aggressive than leiomyomas with low mitotic activity. In the present study, identical X-chromosomal inactivation patterns at both PGK and AR loci were found in seven discrete tumors examined from a case (case 46) otherwise considered a mitotically active leiomyoma. Our Xchromosomal inactivation analysis data revealed the invading capacity of the tumor. Focal coagulative necrosis was detected by re-sampling, and a diagnosis of leiomyosarcoma was made for the case. The subsequent follow-up proved its malignant behavior. Therefore, X-chromosomal inactivation analysis is of diagnostic value for distinction of the leiomyosarcoma from other multinodular smooth muscle neoplasms with elevated mitotic activity.

In the uterus, those with mitotic figures $<5 / 10 \mathrm{HPF}$ are considered non-aggressive, benign lesions (55), while most of the tumors falling into the category of leiomyosarcoma are highly malignant $(56,57)$. Actually, little is known about the invading capacity of uterine leiomyomas, though it may be a more representative parameter for behavior evaluation of the smooth muscle tumors. Between the highly malignant and benign entities of the spectrum, there should be some lesions showing local aggressiveness and classified into benign uterine leiomyoma based on the current criteria. Some of the cases may correspond to the mitotically active leiomyoma, but the relevance remains to be established between the elevation of mitotic activity and acquisition of invading capacity. The intramural spreading usually does not result in extrauterine dissemination or metastasis possibly due to their dependence on hormonal stimuli and anatomical features of the uterus. The occurrence of unicentric multiple leiomyomas, as described above, may reflect the local aggressiveness. There have been several reports describing the presence of some extrauterine smooth muscle tumors associated with multiple uterine leiomyomas (58-62). We think that some of the multiple uterine tumors are unicentric, and that these extrauterine lesions may represent dissemination or metastasis. In this context it is interesting to note that a majority of the clinically aggressive leiomyogenic neoplasms, including IVL (14), BML (1518,54,63-66) and DLP (19,20,67,68), emerge as multiple uterine lesions. Further study is needed for clarification of the clinical behaviors of this tumor type by long-term follow-up surveys.

\section{Acknowledgements}

The authors thank Drs Zhong Zuo, Guochao Chen and Yong Fu for their help in collecting specimens, Lingzhi $\mathrm{Hu}$, Shujie Yang and Jie Liu for their technical assistance, and Professor Peter Bannasch (German Cancer Research Center, Heidelberg) for his critical reading of the manuscript. This study was supported by the Natural Science Foundation of China, grants 30171052 and 30572125, and the Medical and Health Science Research Foundation of Shaanxi Province, China, grant 02D02.

\section{References}

1. Anderson $\mathbf{J}$ and Barbieri RL: Abnormal gene expression in uterine leiomyomas. J Soc Gynecol Invest 2: 663-672, 1995.

2. Cramer SF and Patel A: The frequency of uterine leiomyomas. Am J Clin Pathol 94: 435-438, 1990.

3. Kjerulff KH, Langenberg P, Seidman JD, Stolley PD and Guzinski GM: Uterine leiomyomas: racial differences in severity, symptoms and age at diagnosis. J Reprod Med 41: 483-490, 1996.

4. Perrone T and Dehner LP: Prognostically favorable 'mitotically active' smooth muscle tumors of the uterus: a clinicopathologic study of ten cases. Am J Surg Pathol 12: 1-8, 1988.

5. O'Connor DM and Norris HJ: Mitotically active leiomyomas of the uterus. Hum Pathol 21: 223-227, 1990.

6. Prayson RA and Hart WR: Mitotically active leiomyomas of the uterus. Am J Clin Pathol 97: 12-20, 1992.

7. Dgani R, Piura B, Ben-Baruch G, Open M, Glezerman M, Nass D, Czernobilsky B, Yanai-Inbar I and Elchalal U: Clinicalpathological study of uterine leiomyomas with high mitotic activity. Acta Obstet Gynecol Scand 77: 74-77, 1998.

8. Kempson RL and Bari W: Uterine sarcomas: classification, diagnosis and prognosis. Hum Pathol 1: 331-349, 1970.

9. Mittal K and Demopoulos RI: MIB-1 (Ki-67), p53, estrogen receptor, and progesterone receptor expression in uterine smooth muscle tumors. Hum Pathol 32: 984-987, 2001.

10. Robby SJ, Mehta K and Norris HJ: Malignant potential and pathology of leiomyomatous tumors of the uterus. Clin Consult Obstet Gynecol 2: 2-9, 1990.

11. Bell SW, Kempson RL and Hendrickson MR: Problematic uterine smooth muscle neoplasms: a clinicopathologic study of 213 cases. Am J Surg Pathol 18: 535-558, 1994.

12. Clement PB: The pathology of uterine smooth muscle tumors and mixed endometrial stromal-smooth muscle tumors: a selective review with emphasis on recent advances. Int J Gynecol Pathol 19: $39-55,2000$.

13. Mulvany NJ, Slavin JL, Ostor AG and Fortune DW: Intravenous leiomyomatosis of the uterus: a clinicopathologic study of 22 cases. Int J Gynecol Pathol 13: 1-9, 1994.

14. Arif S, Ganesany R and Spooner D: Intravascular leiomyomatosis and benign metastasizing leiomyoma: an unusual case. Int J Gynecol Cancer 16: 1448-1450, 2006.

15. Parenti DJ, Morley TF and Giudice JC: Benign metastasizing leiomyoma: a case report and review of the literature. Respiration 59: 347-350, 1992.

16. Esteban JM, Allen WM and Schaerf RH: Benign metastasizing leiomyoma of the uterus: histologic and immunohistochemical characterization of primary and metastatic lesions. Arch Pathol Lab Med 123: 960-962, 1996.

17. Tietze L, Gunther K, Horbe A, Pawlik C, Klosterhalfen B, Handt $\mathrm{S}$ and Merkelbach-Bruse S: Benign metastasizing leiomyoma: a cytogenetically balanced but clonal disease. Hum Pathol 31: 126-128, 2000. 
18. Egberts J-H, Schafmayer C, Bauerschlag O, Jänig U and Tepel J: Benign abdominal and pulmonary metastasizing leiomyomas of the uterus. Arch Gynecol Obstet 274: 319-322, 2006.

19. Mark J, Havel G, Dahlenfors R and Wedell B: Cytogenetics of multiple uterine leiomyomas, parametrial leiomyoma and disseminated peritoneal leiomyomatosis. Anticancer Res 11: 33-39, 1991.

20. Quade BJ, McLachlin CM, Soto-Wright V, Zuckerman J, Mutter GL and Morton CC: Disseminated peritoneal leiomyomatosis, clonality analysis by $\mathrm{X}$ chromosome inactivation and cytogenetics of a clinically benign smooth muscle proliferation. Am J Pathol 150: 2153-2166, 1997.

21. Townsend DE, Sparkes RS, Baluda MC and McClelland G: Unicellular histogenesis of uterine leiomyomas as determined by electrophoresis by glucose-6-phosphate dehydrogenase. Am J Obstet Gynecol 107: 1168-1173, 1970.

22. Nilbert M and Strombeck B: Independent origin of uterine leiomyomas with karyotypically identical alterations. Gynecol Obstet Invest 33: 246-248, 1992.

23. Mashal RD, Schoenberg Fejzo ML, Frideman AJ, Mitchner N, Nowak RA, Rein MS, Morton CC and Sklar J: Analysis of androgen receptor DNA reveals the independent clonal origins of uterine leiomyomas and the secondary nature of cytogenetic aberrations in development of leiomyomas. Genes Chromosomes Cancer 11: 1-6, 1994.

24. Hashimoto K, Azuma C, Kamiura S, Kimura T, Nobunaga T, Kanai T, Sawada M, Noguchi S and Saji F: Clonal determination of uterine leiomyomas by analyzing differential inactivation of the X-chromosome-linked phosphoglycerokinase gene. Gynecol Obstet Invest 40: 204-208, 1995.

25. Mantovani MS, Neto JB, Philbert PM and Casartelli C: Multiple uterine leiomyomas: cytogenetic analysis. Gynecol Oncol 72: 71-75, 1999.

26. Fujimoto J, Hirose R, Sakaguchi H and Tamaya T: Expression of size-polymorphic androgen receptor gene in uterine leiomyoma according to the number of cytosine, adenine, and guanine repeats in androgen receptor alleles. Tumour Biol 21: 33-37, 2000.

27. Canevari RA, Pontes A, Rosa FE, Rainho CA and Rogatto SR: Independent clonal origin of multiple uterine leiomyomas that was determined by $\mathrm{X}$ chromosome inactivation and microsatellite analysis. Am J Obstet Gynecol 193: 1395-1403, 2005.

28. Zhang P, Zhang C, Hao J, Sung CJ, Quddus MR, Steinhoff MM and Lawrence WD: Use of X-chromosome inactivation pattern to determine the clonal origins of uterine leiomyoma and leiomyosarcoma. Hum Pathol 37: 1350-1356, 2006.

29. Wang SF, Su Q, Zhu SJ, Liu J, Hu LZ and Li DH: Clonality of multiple uterine leiomyomas. Zhonghua Bing Li Xue Za Zhi 31: 107-111, 2002.

30. Nilbert M and Heim S: Uterine leiomyoma cytogenetics. Genes Chromosomes Cancer 2: 3-13, 1990.

31. Nilbert M, Heim S, Mandahl N, Floderus UM, Willen $H$ and Mitelman F: Characteristic chromosome abnormalities, including rearrangements of $6 p, \operatorname{del}(7 q),+12$, and $t(12 ; 14)$, in 44 uterine leiomyomas. Hum Genet 85: 605-611, 1990.

32. Zaloudek $\mathrm{C}$ and Hendrickson MR: Mesenchymal tumors of the uterus. In: Blaustein's Pathology of the Female Genital Tract. Kurman RJ (ed). Springer-Verlag, New York, pp561-615, 2002.

33. Su Q, Schröder CH, Otto G and Bannasch P: Overexpression of $\mathrm{p} 53$ protein is not directly related to hepatitis $\mathrm{B} \times$ protein expression and is associated with neoplastic progression in hepatocellular carcinomas rather than hepatic preneoplasia. Mutat Res 462: 365-380, 2000.

34. Vogelstein B and Fearon ER: Use of restriction fragment length polymorphism to determine the clonal origin of human tumors. Science 227: 642-644, 1985.

35. Allen RC, Zoghbi HY, Moseley AB, Rosenblatt HM and Belmont JW: Methylation of HpaII and HhaI sites near the polymorphic CAG repeat in the human androgen-receptor gene correlates with X chromosome inactivation. Am J Hum Genet 51: 1229-1239, 1992.

36. Gartler SM and Riggs AD: Mammalian X-chromosome inactivation. Annul Rev Genet 17: 155-190, 1983.

37. Garcia SB, Novelli M and Wright NA: The clonal origin and clonal evolution of epithelial tumors. Int J Exp Pathol 81: 89-116, 2000.

38. Li M, Cordon-Cardo C, Gerald WL and Rosai J: Desmoid fibromatosis is a clonal process. Hum Pathol 27: 939-943, 1996.

39. Schmidt GH and Mead R: On the clonal origin of tumors - lessons from studies of intestinal epithelium. Bioessays 12: 37-40, 1990.
40. Chung I-M, Swartz SM and Murray CE: Clonal architecture of normal and atherosclerotic aorta. Implications for atherogenesis and vascular development. Am J Pathol 152: 913-923, 1998.

41. Guo Z, Thunberg U, Sallstrom J, Wilander E and Ponten J: Clonality analysis of cervical cancer on microdissected archival materials by PCR-based X-chromosome inactivation approach. Int J Oncol 12: 1327-1332, 1998.

42. Lehmann EL: Nonparametrics: statistical methods based on ranks. Holden and Day, San Francisco, 1975.

43. Busque L, Mio R, Mattioli J, Brais E, Blais N, Lalonde Y, Maragh $M$ and Gilliland DG: Nonrandom X-inactivation patterns in normal females: lyonization ratios vary with age. Blood 88: 59-65, 1996

44. Singer-Sam J, Keith DH, Tani K, Simmer RL, Shively L, Lindsay S, Yoshida A and Riggs A: Sequence of the promoter region of the gene for human X-linked 3-phosphoglycerate kinase. Gene 32: 409-417, 1984.

45. Keith DH, Singer-Sam J and Riggs AD: Active X-chromosome DNA is unmethylated at eight CCGG sites clustered in a guanineplus-cytosine-rich island at the end of the gene for phosphoglycerate kinase. Mol Cell Biol 6: 4122-4125, 1986.

46. Kuiper GG, Faber PW, Van Rooij HC, van der Korput JA, Ris-Stalpars C, Klaassen P, Trapman J and Brinkmann AO: Structural organization of the human androgen receptor gene. J Mol Endocrinol 2: R1-R4, 1989.

47. Lubahn DB, Brown TR, Simental JA, Higgs HN, Migeon CJ, Wilson EM and French FS: Sequence of the intron/exon junctions of the coding region of the human androgen receptor gene and identification of a point mutation in a family with complete androgen insensitivity. Proc Natl Acad Sci USA 86: 9534-9538, 1989.

48. Diallo R, Schaefer K-L, Poremba C, Shivazi N, Willmann V, Buerger H, Dockhorn-Dworniczak B and Boecker W: Monoclonality in normal epithelium and in hyperplastic and neoplastic lesions of the breast. J Pathol 193: 27-32, 2001

49. Mittal K, Popiolek D and Demopoulos RI: Uterine myxoid leiomyosarcoma within a leiomyoma. Hum Pathol 31: 398-400, 2000.

50. den Bakker MA, Hegt VN, Sleddens HB, Nuijten AS and Dinjens WN: Malignant mesenchymoma of the uterus, arising in a leiomyoma. Histopathology 40: 65-70, 2002.

51. Levy B, Mukherjee T and Hirschhorn K: Molecular cytogenetic analysis of uterine leiomyoma and leiomyosarcoma by comparative genomic hybridization. Cancer Genet Cytogenet 121: $1-8,2000$.

52. Quade BJ, Dal Cin P, Neskey DM, Weremowicz S and Morton CC: Intravenous leiomyomatosis: molecular and cytogenetic analysis of a case. Mod Pathol 15: 351-356, 2002

53. Morton CC: Many tumors and many genes: genetics of uterine leiomyomata. Am J Pathol 153: 1015-1020, 1998.

54. Patton KT, Cheng L, Papavero V, Blum MG, Yeldandi AV, Adley BP, Luan C, Diaz LK, Hui P and Yang XJ: Benign metastasizing leiomyoma: clonality, telomere length and clinicopathologic analysis. Mod Pathol 19: 130-140, 2006.

55. Wilkinson $\mathrm{N}$ and Rollason TP: Recent advances in the pathology of smooth muscle tumors of the uterus. Histopathology 39: 331-341, 2001

56. Salazar OM, Bonfiglio TA, Patten SF, Keller BE, Feldstein M, Dunne ME and Rudolph J: Uterine sarcomas, natural history, treatment and prognosis. Cancer 42: 1152-1560, 1978.

57. Tavassoli FA and Devilee P: World Health Organization classification of tumors. Pathology and genetics of tumors of the breast and female genital organs. IARC Press, Lyon, 2003.

58. Billings SD, Folpe AL and Weiss SW: Do leiomyomas of deep soft tissue exist? An analysis of highly differentiated smooth muscle tumors of deep soft tissue supporting two distinct subtypes. Am J Surg Pathol 25: 1134-1142, 2001.

59. Meniru G-I, Wasdahl D, Onuora C-O, Hecht B-R and Hopkins M-P: Vaginal leiomyoma co-existing with broad ligament and multiple uterine leiomyomas. Arch Gynecol Obstet 265: 105-107, 2001.

60. Prayson RA and Hart WR: Primary smooth-muscle tumors of the ovary, a clinicopathologic study of four leiomyomas and two mitotically active leiomyomas. Arch Pathol Lab Med 116: 1068-1071, 1992.

61. Cho KR, Woodruff JD and Epstein JI: Leiomyoma of the uterus with multiple extrauterine smooth muscle tumors: a case report suggesting multifocal origin. Hum Pathol 20: 80-83, 1989. 
62. Horiuchi K, Yabe H, Mukai M, Morioka H, Udagawa Y, Nozawa S and Yabe Y: Multiple smooth muscle tumors arising in deep soft tissue of lower limbs with uterine leiomyomas. Am J Surg Pathol 22: 897-901, 1998.

63. Kayser K, Zink S, Schneider T, Dienemann H, Andre S, Kaltner H, Schuring MP, Zick Y and Gabius HJ: Benign metastasizing leiomyoma of the uterus: documentation of clinical, immunohistochemical and lectin-histochemical data of ten cases. Virchows Arch 437: 284-292, 2000.

64. Goyle KK, Moore DF Jr, Garrett C and Goyle V: Benign metastasizing leiomyomatosis: case report and review. Am J Clin Oncol 26: 473-476, 2003.
65. Funakoshi Y, Sawabata N, Takeda S, Hayakawa M, Okumura Y and Maeda H: Pulmonary benign metastasizing leiomyoma from the uterus in a postmenopausal woman: report of a case. Surg Today 34: 55-57, 2004.

66. Gómez FJT, Tristán A and Olivera FJT: Benign metastasizing leiomyoma of the lung. Arch Bronchoneumol 43: 52-53, 2007.

67. Karuppaswamy J and Tapp A: Leiomyomatosis peritonealis disseminata, is a different approach needed? J Obstet Gynaecol 22: 446-456, 2002.

68. Heinig J, Neff A, Cirkel U and Klockenbusch W: Recurrent leiomyomatosis peritonealis disseminata after hysterectomy and bilateral salpingo-oophorectomy during combined hormone replacement therapy. Eur J Obstet Gynecol Reprod Biol 111: 216-218, 2003. 